\title{
PENGARUH FAKTOR-FAKTOR KEPUASAN KERJA TERHADAP KOMITMEN ORGANISASI PADA MTS DAN SMK
}

\section{THE EFFECT OF WORK SATISFACTION FACTORS TOWARD ORGANIZATIONAL COMMITMENT IN MTS AND VOCATIONAL SCHOOLS}

\author{
Airahmawati1a, Sudarijati ${ }^{1}$, dan $S$ Harini' ${ }^{1}$ \\ ${ }^{1}$ Fakultas Ekonomi, Universitas Djuanda Bogor, Jl. Tol Ciawi No. 1 Kotak Pos 35 Ciawi Bogor 16720 \\ a Korespondensi: Airahmawati, Email: airahmawati268@gmail.com \\ (Diterima: 21-01-2018; Ditelaah: 22-01-2018; Disetujui: 20-03-2018)
}

\begin{abstract}
This aim of this research is to examine the influence factors of work satisfaction of organizational commitment at MTs and SMK TERPADU YAPISA Megamendung Bogor Regency. This research is classified as descriptive and verificative. The data collection was done through questionnaires to 47 teachers in MTs and SMK TERPADU YAPISA Megamendung Bogor Regency. Secondary and primary data are used in this research. The result of this research is that factors of work satisfactions are simultaneusly influenced and also showed a positive connection towards organizational commitment at MTs and SMK TERPADU YAPISA Megamendung Bogor Regency. Partially, work satisfaction, salary, promotion, supervision, co-worker, and work condition are significantly and positively influenced to the organizational commitment. For the next research, we suggest that continous analysis on factors which can increase organizational commitment beside work satisfaction factors (work experience, work characteristics, structure charateristics, task interaction, etc) should be done.
\end{abstract}

Key words: job satisfaction factors, organizational commitment.

\begin{abstract}
ABSTRAK
Penelitian ini bermaksud memverifikasi pengaruh faktor-faktor kepuasan kerja terhadap komitmen organisasi pada MTs dan SMK Terpadu YAPISA Megamendung Kabupaten Bogor. Penelitian ini digolongkan pada penelitian yang bersifat verifikatif serta deskriptif. Pengumpulan data dilakukan melalui cara menyebarkan kuesioner kepada 47 guru pada MTs dan SMK Terpadu YAPISA Megamendung-Kabupaten Bogor. Data primer dan sekunder adalah data yang dipakai pada penelitian ini. Hasil penelitian faktor-faktor kepuasan kerja secara bersama-sama berpengaruh signifikan serta positif terhadap komitmen organisasi pada MTs dan SMK Terpadu Yapisa Megamendung Kabupaten Bogor, secara parsial kepuasan pekerjaan, gaji, promosi, supervisi, rekan kerja serta kondisi kerja berpengaruh signifikan serta positif pada komitmen organisasi. Untuk penelitian berikutnya disarankan menganalisa berkaitan faktor-faktor yang akan menaikkan komitmen organisasi selain faktor-faktor kepuasan kerja yaitu pengalaman kerja, karakteristik pekerjaan, karakteristik struktur, interaksi tugas.

Kata kunci: faktor-faktor kepuasan kerja, komitmen organisasi.
\end{abstract}

Septiana, A., Harini, S., \& Sudarijati. 2018. Pengaruh Faktor-Faktor Kepuasan Kerja terhadap Komitmen Organisasi pada MTS dan SMK. Jurnal Sosial Humaniora 9(1): 48-60. 


\section{PENDAHULUAN}

Organisasi merupakan kumpulan dari beberapa orang yang saling bekerja sama menggapai tujuan yang sama. Menggapai tujuannya, organisasi memiliki faktor pendukung yang penting, salah satunya yaitu karyawan. Karyawan yang bekerja harus berkualitas serta profesional dalam bekerja, karena profesionalisme dari karyawan tersebut menggambarkan tingginya kepuasan kerja dari pekerja dapatkan. Karyawan mempunyai rasa kepuasantinggi terhadap pekerjannya pada organisasi cenderung akan memegang teguh rasa komitmen pada tempatnya bekerja, karena rasa kepuasan akan seluruh kebutuhan juga keinginannya terpenuhi dengan baik dari hasil kerjanya. Komitmen yang telah dimiliki pekerja tersebut akan mampu membantu pencapaian keberhasilan dari organisasi.

Luthans (2006), mengatakan elemen kepuasan kerja harus terpenuhi seperti kepuasan pekerjaan, kepuasan gaji, kepuasan promosi, kepuasan supervisi, kepuasan rekan kerja dan kepuasan kondisi kerja sebaiknya sama kebutuhan dan juga dengan keinginan karyawan. Dengan pemenuhan elemen kepuasan kerja tersebut, maka akan tercipta komitmen organisasi dari para pekerja yang puas terhadap pekerjannya, sedangkan menurut Sopiah (2008), komitmen organisasi juga memiliki faktor penentu keberhasilanya yaitu faktor personal, karakteristik pekerjaan, karakteristik struktur. Serta sebagai faktor internal berhubungan mengenai komitmen organisasi yang perlu dipertahankan untuk kemajuan organisasi tersebut yang akan menghasilkan komitmen organisasi meningkat dari pekerja di dalamnya. Kepuasan kerja mencerminkan tinggi dan rendahnya komitmen dari karyawan pada tempatnya bekerja. Salah satu organisasi pendidikan yang berbasis Agama yaitu Yayasan Pendidikan Islam Terpadu Sa'id Abdurachman (YAPISA) Yayasan yang memiliki Guru untuk membantu pencapaian tujuan.

Guru merupakan pengajar penting bagi sebuah organisasi yang berbasis pendidikan, karena tujuan yayasan dalam membuat para murid berkualitas, unggul berdasarkan imtak serta iptek yang diwujudkan melalui berbagai peran dari guru termasuk proses belajar mengajar. Ketidakpuasan para guru diperlihatkan dengan ketidakhadirannya dalam mengajar. Menurut Tabel 1 tingkat kehadiran guru pada periode Agustus 2016 - Januari 2017 kurang dari $100 \%$. Padahal menurut wawancara dengan Ketua YAPISA, target guru melakukan proses KBM di sekolah diharapkan mencapai tingkat kehadiran 100\%. Rincian tingkat kehadiran guru MTs dan SMK pada periode Agustus 2016 Januari 2017 yang diterangkan pada Tabel 1.

Tabel 1 Tingkat kehadiran guru MTs dan SMK Terpadu YAPISA Megamendung periode Agustus 2016 - Januari 2017

\begin{tabular}{lrllr}
\hline \multicolumn{1}{r}{ Bulan } & \multicolumn{1}{r}{ Tingkat Kehadiran (\%) } & \multicolumn{1}{r}{ Bulan } & \multicolumn{2}{r}{ Tingkat Kehadiran (\%) } \\
\hline & Guru MTs & & & Guru SMK \\
\hline Agustus & 73 & Agustus & & 67 \\
September & 71 & September & & 68 \\
Oktober & 72 & Oktober & & 68 \\
November & 70 & November & & 70 \\
Desember & 74 & Desember & & 72 \\
Januari & 71 & Januari & & 65 \\
Total & 431 & Total & 410 \\
Rata-Rata & 71.833 & Rata-Rata & & 68.333 \\
\hline
\end{tabular}

Sumber: Data-Data MTs dan SMK YAPISA Megamendung, 2017.

Selain itu, hasil wawancara awal dengan ketidakhadiran tersebut dikarenakan ketua yayasan menunjukkan bahwa banyaknya guru-guru yang mengajar juga 
pada tempat lain dan mengabaikan tugas di MTs dan SMK YAPISA Megamendung. Hal ini mencerminkan rendahnya komitmen guru terhadap organisasi. Alasan para guru tersebut dikarenakan gaji yang diterima cukup relatif rendah. Pada lembaga ini, sistem gaji yang diterapkan yaitu sesuai dengan tariff perjam kehadirannya yang ditetapkan. Hal tersebut diartikan bahwa sebagai guru yang harus mempunyai tanggung jawab pada pekerjaannya rendah serta kurangnya rasa dari kesadaran guru dalam menurunkan tingkat ketidakhadirannya dalam mengajar, sehingga akan terganggunya pencapaian tujuan. Selain itu, tingkat kehadiran guru yang cukup rendah setiap bulannya dengan rata-rata $71.833 \%$ pada guru MTs dan $68.333 \%$ pada guru SMK. Akibatnya siswa sering ada di luar dari kendali guru yang hadir.

\section{MATERI DAN METODE}

Materi

\section{Kepuasan Kerja}

Kepuasan kerja menurut Handoko (2007), ialah situasi emosional dari diri seorang pekerja yang tidak menyenangkan dan menyenangkan sebagaimana karyawan tersebut melihat pekerjaannya. Menurut Luthans (2006), beberapa faktor-faktor dari kepuasan kerja digunakan menilai kepuasan kerja yaitu:

1. Kepuasan pekerjaan itu sendiri

Menurut Handoko (2002), pekerjaan merupakan kegiatan yang dikerjakan oleh setiap karyawan dalam memenuhi kewajibannya sebagai pekerja atau perusahaan, pekerjaan-pekerjaan tersebut bagaikan jembatan karyawan dengan organisasi.

2. Kepuasan Gaji

Menurut Handoko (2002), gaji yaitu pemberian pembayaran financial yang diterima pekerja sebagai motivasi dalam pelaksanaan kegiatan di masa mendatang.

3. Kepuasan Promosi

Menurut Flippo (2006), merupakan perubahan pekerjaan dari satu ke lainnya dengan syarat yang lebih dalam kedudukan, tanggung jawab serta tugas dari pekerjaannya.

4. Kepuasan Supervisi

Menurut Luthans (2006), supervisi merupakan afiliasi fungsional yang menjelaskan atasan dalam mendukung pekerja dalam memenuhi nilai penting bagi karyawan.

5. Kepuasan Rekan kerja

Menurut Handoko (2002), rekan kerja ialah hubungan keterkaitan sepihak yang fungsional, karena mereka ada pada satu ruang sama sehingga dapat berkomunikasi.

6. Kepuasan Kondisi kerja

Menurut Mangkunegara (2002), kondisi kerja yaitu beberapa aspek fisik, aspek psikologis serta aturan kerja dapat mempengaruhi kepuasan kerja serta pencapain produktivitas kerja.

\section{Komitmen Organisasi}

Komitmen organisasi menurut Luthans (2006), yaitu kemauan kuat ingin menjadi bagian organisasi tertentu, komitmen organisasi juga merupakan adanya kemauan berusaha dengan baik dan sesuai serta kepercayaan, serta penerimaan nilai juga tujuan organisasi dengan tiga aspek komitmen organisasi diantaranya affectif commitment, continuance commitment dan normative commitment.

\section{Hipotesis}

Hipotesis dinyatakan bahwa variabel $\mathrm{X}$ secara simultan berpengaruh signifikan dan positif terhadap variabel $Y$ sedangkan secara parsial seluruh variabel $\mathrm{X}$ secara parsial mempunyai pengaruh positif serta signifikan terhadap variabel Y. 


\section{Metode}

Penelitian dilakukan guna mendapatkan gambaran tentang pengaruh dari variabel $X$ terhadap variabel $Y$ MTs dan SMK Terpadu YAPISA Megamendung Kabupaten Bogor. Dalam pelaksanaan penelitian ini, akan digunakan penelitian verifikatif serta deskriptifyang dilaksanakan dengan penghimpunan datadata di lapangan. Adapun penelitian verifikatif yaitu dipakai memverifikasi hipotesis menggunakan statistik (Nasir 2003). Sedangkan jenis data primer yang digunakan dengan metode wawancara juga menggunakan kuesioner. Objek penelitian

Tabel 2 Operasionalisasi variabel dilakukan pada guru MTs dan SMK terletak di Jln. Cikopo Selatan KM.6 Pasir Muncang RT 01/01 Desa Sukaresmi, Kec Megamendung, Kab Bogor, Kode Pos 16770.

\section{Operasionalisasi Variabel}

Variabel yang dipakai yaitu kepuasan pekerjaan itu sendiri $\left(\mathrm{X}_{1}\right)$, kepuasan gaji $\left(\mathrm{X}_{2}\right)$, kepuasan promosi $\left(\mathrm{X}_{3}\right)$, kepuasan supervisi $\left(\mathrm{X}_{4}\right)$, kepuasan rekan kerja $\left(\mathrm{X}_{5}\right)$ dan kepuasan kondisi kerja $\left(\mathrm{X}_{6}\right)$ serta variabel terikat ialah komitmen organisasi (Y). Operasionalisasi variabel terdapat di Tabel 2.

\begin{tabular}{|c|c|c|c|c|c|}
\hline Variabel & Konsep Variabel & & Indikator & $\begin{array}{l}\text { Skala } \\
\text { Ukur }\end{array}$ & Item \\
\hline $\begin{array}{l}\text { Kepuasan } \\
\text { pekerjaan itu } \\
\text { sendiri (X1) }\end{array}$ & $\begin{array}{l}\text { Karakteristik dan } \\
\text { kompleksitas pekerjaan } \\
\text { menghubungkan yaang } \\
\text { antara kepribadian dan } \\
\text { kepuasan kerja (Luthans, } \\
\text { 2006). }\end{array}$ & & $\begin{array}{l}\text { Perasaan berarti } \\
\text { Tanggung jawab } \\
\text { Pengetahuan terhadap } \\
\text { hasil }\end{array}$ & Ordinal & $\begin{array}{l}1-2 \\
3-5 \\
6-7\end{array}$ \\
\hline $\begin{array}{l}\text { Kepuasan } \\
\text { gaji }(\mathrm{X} 2)\end{array}$ & $\begin{array}{l}\text { Terpuaskannya seseorang } \\
\text { dengan gaji ketika persepsi } \\
\text { dan yang diperoleh sesuai } \\
\text { harapan (Suwandi, 2009) }\end{array}$ & $\begin{array}{l}1 . \\
2 . \\
3 .\end{array}$ & 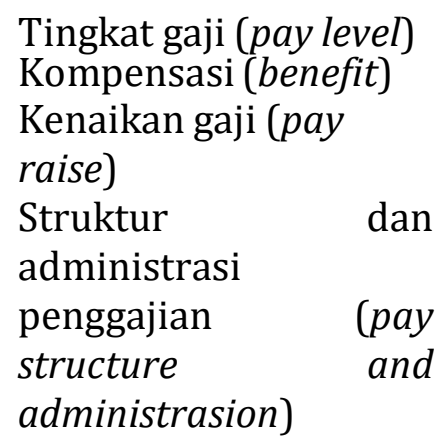 & Ordinal & $\begin{array}{c}8-9 \\
10-11 \\
12-13 \\
14-15\end{array}$ \\
\hline $\begin{array}{l}\text { Kepuasan } \\
\text { promosi (X3) }\end{array}$ & $\begin{array}{l}\text { Perpindahan yang } \\
\text { membesar authority dan } \\
\text { responsibility karyawan ke } \\
\text { yang lebih meningkat } \\
\text { sehingga kewajibannya } \\
\text { bertambah semakin besar. } \\
\text { (Hasibuan, 2008) }\end{array}$ & $\begin{array}{l}1 . \\
2 . \\
3 .\end{array}$ & $\begin{array}{l}\text { Kepercayaan } \\
\text { Keadilan } \\
\text { Formasi }\end{array}$ & Ordinal & $\begin{array}{l}16-17 \\
18-19 \\
20-21\end{array}$ \\
\hline $\begin{array}{l}\text { Kepuasan } \\
\text { supervisi (X4) }\end{array}$ & $\begin{array}{l}\text { Hubungan fungsional yang } \\
\text { Menggambarkan seorang } \\
\text { atasan dalam membantu } \\
\text { karyawan untuk } \\
\text { menyelesaikan nilai-nilai } \\
\text { penting untuk pekerja. } \\
\text { (Luthans, 2006) }\end{array}$ & $\begin{array}{l}1 . \\
2 .\end{array}$ & $\begin{array}{l}\text { Employee centeredness } \\
\text { Participation or } \\
\text { influence }\end{array}$ & Ordinal & $25-26$ \\
\hline $\begin{array}{l}\text { Kepuasan } \\
\text { rekan kerja } \\
\text { (X5) }\end{array}$ & $\begin{array}{l}\text { Bagian dari kebutuhan } \\
\text { sosial pada tempat kerja } \\
\text { yang didapatkan bukan }\end{array}$ & 1. & $\begin{array}{l}\text { Rekan kerja yang } \\
\text { memiliki ilmu } \\
\text { pengetahuan }\end{array}$ & Ordinal & $27-29$ \\
\hline
\end{tabular}


hanya materi atau prestasiprestasi berwujud namun kebutuhan interaksi sosial. (Robbins, 2003)

$\begin{array}{llr}\text { Kepuasan } & \text { Kondisi kerja dari } \\ \text { kondisi kerja } & \text { karyawan yang } & \\ \text { (X6) } & \text { prihatin dengan lingkungan } \\ & \text { kerja mereka, menyangkut } \\ & \text { kenyamanan } & \text { untuk } \\ & \text { kebutuhan } & \text { pribadi. } \\ & \text { (Robbins, 2003) } & \end{array}$

Komitmen Organisasi (Y)

Keinginan beruasaha
keras serta
keyakinan tertentu, dan
penerimaan nilai juga
tujuan organisasi. (Luthans,
2006)

\section{Sampel Penelitian}

Untuk menentukan unit analisis pada yayasan tempat penelitian ialah seluruh guru dengan jumlah 47 orang guru. Penelitian ini memakai total sampling, adalah sampel diambil merupakan dari keseluruhan populasi yang berjumlah 47 guru. Menurut Arikunto (2006), jika subjeknya < dari seratus untuk pengambilan sampel, lebih baik untuk mengambil seluruh sampel tersebut maka penelitian adalah populasi. Sedangkan data primer adalah data didapatkan lewat jawaban objek penelitian melalui kuesioner yang disediakan, yaitu berupa data mengenai fenomena pendapat atau fenomena dari objek. Sedangkan data sekunder diperoleh melalui study kepustakaan yang dikumpulkan melalui baca serta pelajari literature, buku, jurnal, skripsi, dari data internet dan data-data laporan yayasan. Sedangkan untuk pengumpulan data yaitu: 1) riset lapangan terdiri dari: kuesioner, wawancara,
2. Rekan kerja yang suka mendengarkan

3. Atasan langsung yang memiliki ilmu pengetahuan

4. Atasan langsung yang suka memberi pertolongan

1. Sirkulasi udara, keadaan cahaya

Ordinal

2. Bising suara

3. Kebersihan dan $42-44$ kemodernan fasilitas kerja

4. Kelengkapan peralatan termasuk tanda-tanda bahaya di lingkungan kerja

5. Kelengkapan fasilitas kesehatan

1. Affective commitment Ordinal 49-53

2. Continuance 54-58 commitment

3. Normative commitment

observasi; 2) metode riset kepustakaan, dalam melakukan study pustaka, penulis mengkaji teori bersangkutan dengan pemasalahan.

\section{Pengujian Instrument}

Uji validitas dalam penelitian dilakukan menguji tidak valid atau validnya kuesioner, adapun pengujian validitas yaitu jika dari hasil tersebut diperoleh $r_{\text {hitung }} \geq r$ tabel maka data valid yang berarti layak digunakan, sedangkan $\mathrm{r}$ hitung $<\mathrm{r}$ tabel menunjukan bahwa data tidak valid yang artinya data itu tidak layak dengan kriteria $\mathrm{r}_{\text {tabel }}$ yaitu 0,3.

Berdasarkan uji validitas pada pernyataan variabel dari variabel $X$ serta komitmen variabel $\mathrm{Y}$ menggambarkan instrument dikatakan valid karena nilai korelasi sesuai dengan nilai yang dipakai yaitu rhitung $\geq$ rtabel yang dijelaskan bahwa nilai-nilai itu lebih besar sama yaitu $(\geq 0,3)$.

Sedangkan untuk mengukur koefisien keandalan (reability) kuesioner 
menggunakan cara Cronbach Alpha diuji pada alpha 0 (nol) - 1 (satu). Dengan kriteria pengujian reliabilitas adalah jika $r$ hitung $\geq$ $r_{\text {tabel }}$ yang berarti reliabel, serta sebaliknya jika $r_{\text {hitung }}<r_{\text {tabel }}$ yang artinya tidak reliabel. Suatu instrument dapat dinyatakan reliabel jika memiliki nilai alpha 0,6 atau lebih. Dengan hasil perhitungan yang menghasilkan bahwa variabel penelitian ini memenuhi uji reliabilitas dimana alpha $\geq 0,6$. Dengan demikian, maka semua variabel penelitian dinyatakan reliable karena didapatkan hasil $r_{\text {hitung }} \geq r_{\text {tabel }}$.

\section{Uji Asumsi Klasik}

\section{Uji Normalitas}

Berdasarkan uji ini memakai grafik P-Plot dimana gambar P-Plot yang dapat diartikan bahwa data terdistribusi normal sebab data menyebar dan mengikuti arah garis diagonal, jadi model regresi memenuhi normalitas dan model regresi telah memenuhi uji asumsi normalitas. Sedangkan untuk mendukung dan membuktikan hasil uji normalitas grafik perlu dilakukan Kolmogorov-Smirnov, output yang diketahui nilai dari signifikasi (Asymp.Sig 2-tailed) sebesar 0,639. Karena signifikasi $>0,05(0,639>0,05)$ maka disimpulkan data yang telah diuji berdistribusi normal.

\section{Uji Multikolinearitas}

Batasan yang dipakai ialah nilai tolerance $>$ 0,05 atau VIF $<5$. Model regresi linier berganda baik adalah terbebas dari multikolinearitas sehinga dipakai pada penelitian. Berdasarkan dari hasil uji multikolienaritas yang telah analisis nilai tolerance variabel bebas $\left(\mathrm{X}_{1}\right) 0,731,\left(\mathrm{X}_{2}\right)$ 0,767, ( $\left.X_{3}\right)$ 0,893, $\left(X_{4}\right)$ 0,895, $\left(X_{5}\right) 0,926$ dan $\left(\mathrm{X}_{6}\right)$ 0,956 yang berarti $(>0,05)$. Sementara untuk hasil dari nilai VIF $\left(\mathrm{X}_{1}\right)$ 1,368, $\left(X_{2}\right)$ 1,303, $\left(X_{3}\right)$ 1,120, $\left(X_{4}\right) 1,117,\left(X_{5}\right)$ 1,080 dan $\left(\mathrm{X}_{6}\right)$ 1,045 yang dapat diartikan bahwa seluruh variabel bebas $<5$, sehingga model regresi penelitian tidak terjadi masalah uji ini.

\section{Uji Heterokedastisitas}

Pengujian ini bermaksud mengetahui sama atau perbedaan varian suatu residual antar pengamata. Berdasarkan hasil penggujian heteroskedastisitas mengartikan tidak ada heteroskedastisitas pada model persamaan regresi, sehingga dinyatakan layak untuk digunakan dalam memprediksi komitmen organisasi karena titik-titik pada sumbu Y dengan menyebar di atas dan di bawah angka 0 tanpa membentuk pola tertentu.

\section{Metode Analisis dan Langkah- Langkahnya}

Melalui skala Likert variabel diukur dijabarkan dengan memperhatikan tanggapan responden, deskripsi tersebut digunakan untuk menghitung scoring dan nilai rata-rata seperti pada Tabel 3 .

Tabel 3 Skala pengukuran variabel

\begin{tabular}{lr}
\hline \multicolumn{1}{c}{ Alternatif Jawaban } & Skor \\
\hline Sangat setuju & 5 \\
Setuju & 4 \\
Netral & 3 \\
Tidak setuju & 2 \\
Sangat tidak setuju & 1 \\
\hline
\end{tabular}

Sumber: Sugiyono, 2013

Untuk mengukur pengaruh antara suatu variabel terikat dengan dua atau lebih variabel bebas persamaan atau fungsi dalam regresi sebagai berikut.

$Y=a+\beta_{1} X_{1}+\beta_{2} X_{2}+\beta_{3} X_{3}+\beta_{4} X_{4}+\beta_{5} X_{5}+\beta_{6} X_{6}+e$

Analisis korelasi berganda menurut Sugiyono (2013), menjelaskan kuatnya hubungan dari dua variabel atau lebih variabel independent secara bersama-sama terhadap satu variabel dependent. Dengan pedoman penafsiran dari korelasi besar kecilnya seperti pada Tabel 4.

Koefisien determinasi menurut Ghozali (2005), dapat digunakan dalam mengukur kemampuan model dalam menerangkan variasi variabel terikat yang dengan menggunakan:

$\mathrm{KD}=\mathrm{r}^{2} \times 100 \%$ 
Tabel 4 Interpretasi nilai $\mathrm{r}$

\begin{tabular}{ll}
\hline \multicolumn{1}{c}{ Interval Nilai $r$} & \multicolumn{1}{c}{ Interpretasi } \\
\hline $0,001-0,200$ & Sangat lemah \\
$0,201-0,400$ & Lemah \\
$0,401-0,600$ & Cukup kuat \\
$0,601-0,800$ & Kuat \\
$0,801-1,000$ & Sangat kuat \\
\hline
\end{tabular}

Sumber: Sugiyono, 2013

Uji $\mathrm{F}$ dilakukan untuk melihat pengaruh variabel independent secara simultan terhadap variabel dependent. (Ghozali, 2005), dan untuk menguji signifikan hubungan variabel bebas dengan variabel terikat secara simultan. (Sugiyono, 2013). Dengan rumus Uji F sebagai berikut.

$$
F=\frac{R^{2} / K}{\left(1-R^{2}\right) /(n-K-1)}
$$

Untuk menguji pengaruh secara parsial digunakan uji $t$ dengan asumsi tingkat signifikan $(\alpha)$ sebesar 0,05. Dengan tahap perumusan hipotesis, menentukan tingkat signifikansi $(\alpha)$, (dk) derajad kebebasan dengan rumus n-k-1. Menurut Sugiyono (2013), adapun rumus pada Uji t yaitu:

$$
t=\frac{r(n-2)}{\left(1-r^{2}\right)}
$$

Hasil dari pengujian hipotesis tersebut adalah:

a) Bila thitung lebih kecil dari atau sama dengan $t_{\text {tabel }}\left(t_{\text {hitung }} \leq t_{\text {tabel }}\right)$ pada $\alpha=0,05$ maka Ho diterima dan Ha ditolak.

b) Bila $t_{\text {hitung }}$ lebih besar dari $t_{\text {tabel }}\left(t_{\text {hitung }}>\right.$

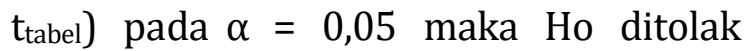
dan Ha diterima.

\section{HASIL DAN PEMBAHASAN}

Pada tahun 1994 Yayasan Pendidikan Islam Tarbiyatul Falah mendirikan MTs yang berdiri di Kecamatan Megamendung Kabupaten Bogor. Awal proses KBM pada MTs Terpadu Yapisa dilaksanakan dengan menumpang di Madrasah Iptidaiah, pada pertengahan tahun 2005, MTs Terpadu
Yapisa mengalami perubahan nama dan kepengurusan yayasan. Semula bernama MTs Tarbiyatul Falah menjadi MTs Terpadu Yapisa. Yayasan Pendidikan Islam Sa'id Abdurachman atau YAPISA, dengan nama tersebut pula saat tahun 2008 kembali mendirikan sekolah tingkat menengah kejuruan sebagai sekolah menegah pertama di Kp Pasir Muncang, Kec Megamendung.

\section{Deskripsi Responden}

Karakteristik guru dapat dijelaskan berdasarkan dari jenis kelamin, usia, masa kerja, pendidikan terakhir, status pernikahan, jumlah beban tanggungan keluarga dan mengajar ditempat lain. Kuesioner disebar kepada 47 Guru dengan uraian seperti pada Tabel 5.

Tabel 5 Rekapitulasi karakteristik guru

\begin{tabular}{lll}
\hline Kriteria & Presentase & Keterangan \\
\hline Jenis kelamin & $72 \%$ & $\begin{array}{l}\text { Laki-Laki } \\
\text { Usia }\end{array}$ \\
$\begin{array}{l}\text { Masa kerja } \\
\text { Mahun }\end{array}$ & $51 \%$ & $\begin{array}{l}1 \text { s/d } 10 \\
\text { Tahun } \\
\text { S1 }\end{array}$ \\
$\begin{array}{l}\text { Pendidikan } \\
\text { terakhir }\end{array}$ & $77 \%$ & Menikah \\
$\begin{array}{l}\text { Status } \\
\text { pernikahan }\end{array}$ & $83 \%$ & 4 s/d 5 \\
$\begin{array}{l}\text { Jumlah beban } \\
\text { tanggungan } \\
\text { keluarga } \\
\begin{array}{l}\text { Mengajar } \\
\text { tempat lain }\end{array}\end{array}$ & $38 \%$ & \\
\hline
\end{tabular}

Berdasarkan Tabel 5 disimpulkan guru sebanyak $72 \%$ adalah laki-laki karena tanggung jawab seorang laki-laki sebagai kepala keluarga untuk mencari nafkah adalah mutlak sebagai beban yang harus dijalankan bagi serorang laki-laki, dengan usia $\quad>45 \quad$ sebanyak $38 \%$ menggambarkanpada usia tersebut para guru mayoritas sudah tidak lagi berada pada usia produktif, dengan masa kerja $1 \mathrm{~s} / \mathrm{d}$ 10 tahun sebanyak 51\% menggambarkan pesatnya perkembangan sekolah dengan 
ditandai bertambahnya murid setiap tahun ajaran baru, serta berpendidikan S1 sebesar 77\% menggambarkan masih adanya guru yang mempunyai pendidikan belum lulus S1, namun guru-guru tersebut dalam proses melanjutkan studi, dengan status guru menikah sebanyak 83\% menggambarkan guru mengajar merupakan guru dengan status pernikahan yang dominan karena umur para guru sudah masuk usia pernikahan, mempunyai beban keluarga 4 s/d 5 tanggungan sebanyak $38 \%$ menunjukkan bahwa tanggungan setiap guru mayoritas sebanyak $4 \mathrm{~s} / \mathrm{d} \quad 5$ tanggungan keluarga, dimana kebanyakan guru memiliki umur lebih dari 45 tahun dan status pernikahan yang mayoritas menikah membuat jumlah tanggungan guru menjadi banyak dan guru mengajar pada tempat lain sebanyak 53\% dikarenakan masih belum terpenuhinya kebutuhan keluarga, sehingga perlu mencari tambahan pendapatan dengan mengajar pada sekolah lain.

Adapun tanggapan guru mengenai variabel kepuasan pekerjaan itu sendiri terdapat pada Tabel 6 .

Tabel 6 Rekapitulasi tanggapan guru mengenai kepuasan pekerjaan itu sendiri

\begin{tabular}{llrl}
\hline No & Uraian & Penilaian responden & Keterangan \\
\hline 1 & Tugas yang dikerjakan merupakan kegiatan & 4,23 & Sangat \\
& berarti & & puas \\
2 & Tugas mengajar memberikan manfaat & 3,32 & Cukup puas \\
3 & Tugas dan tanggung jawab pekerjaan & 3,30 & Cukup puas \\
4 & Tanggung jawab terhadap peralatan & 3,20 & Cukup puas \\
5 & Tanggung jawab terhadap pekerjaan & 3,23 & Cukup puas \\
6 & Tujuan mengajar & 3,47 & Puas \\
7 & Keberhasilan pekerjaan & 3,56 & Puas \\
Rata-rata & 3,47 & Puas \\
\hline
\end{tabular}

Berdasarkan Tabel 6 disimpulkan kepuasan pekerjaan itu sendiri pada MTs dan SMK YAPISA dalam mendidik dan membina siswa dengan nilai rata-ratapuas karena guru merasa pekerjaan dilakukan memiliki banyak dampak yang murid terima, sehingga pekerjaan yang dipahami dengan baik merupakan kunci keberhasilan pekerjaan pada proses belajar mengajar. Adapun rekapitulasi tanggapan guru terhadap kepuasan gaji pada Tabel 7.

Tabel 7 Rekapitulasi tanggapan guru mengenai kepuasan gaji

\begin{tabular}{llrl}
\hline No & \multicolumn{1}{c}{ Uraian } & Penilaian responden & Keterangan \\
\hline 1 & Tingkat gaji yang diterima sesuai beban pekerjaan & 2,79 & Cukup puas \\
2 & Tingkat gaji yang diberikan secara proporsional & 2,57 & Tidak puas \\
3 & Pembayaran kompensasi tepat waktu & 2,70 & Cukup puas \\
4 & Kompensasi yang diberikan sesuai kinerja & 2,55 & Tidak puas \\
5 & Kenaikan gaji sesuai beban pekerjaan & 2,57 & Tidak puas \\
6 & Kenaikan gaji sesuai prestasi kerja & 2,49 & Tidak puas \\
7 & Gaji yang diterima & 2,70 & Cukup puas \\
8 & Penggajian dilakukan secara transparan & 2,74 & Cukup puas \\
Rata-rata & 2,63 & Puas \\
\hline
\end{tabular}


Berdasarkan Tabel 7 disimpulkan indikator kepuasan gaji pada MTs dan SMK YAPISA berada dalam kategori cukup puas, hal ini dikarenakan penerimaan gaji dan beban pekerjaan yang kurang seimbang dan tidak proporsional. Adapun rekapitulasi tanggapan guru terhadap kepuasan promosi pada Tabel 8.

Tabel 8 Rekapitulasi tanggapan guru mengenai kepuasan promosi

\begin{tabular}{llrl}
\hline No & \multicolumn{1}{c}{ Uraian } & Penilaian responden & Keterangan \\
\hline 1 & Kepercayaan sekolah & 3,98 & Puas \\
2 & Promosi jabatan & 3,06 & Cukup Puas \\
3 & Kesempatan promosi jabatan & 3,06 & Cukup Puas \\
4 & Informasi promosi jabatan & 3,02 & Cukup Puas \\
5 & Promosi jabatan kosong & 3,09 & Cukup Puas \\
6 & Promosi berdasarkan formasi & 3,26 Cukup Puas \\
\multicolumn{2}{l}{ Rata-rata } & 3,25 Cukup Puas \\
\hline
\end{tabular}

Berdasarkan Tabel 8 disimpulkan kepuasan promosi pada MTs dan SMK YAPISA berada dalam kategori cukup puas karena perkembangan pekerjaan atau jabatan yang lebih tinggi kurang terlihat dan terjadi di sekolah. Adapun rekapitulasi tanggapan guru terhadap kepuasan supervisi pada Tabel 9.

Tabel 9 Rekapitulasi tanggapan guru mengenai kepuasan supervisi

\begin{tabular}{llcl}
\hline No & \multicolumn{1}{c}{ Uraian } & Penilaian responden & Keterangan \\
\hline 1 & Pengawasan guru & 3,83 & Puas \\
2 & Perhatian masalah & 3,62 & Puas \\
3 & Kepala sekolah mampu memotivasi guru & 3,64 & Puas \\
4 & Kebebasan mengambil keputusan & 3,57 & Puas \\
5 & Penghargaan terhadap hasil kerja & 3,57 Puas \\
Rata-rata & 3,65 Puas \\
\hline
\end{tabular}

Berdasarkan Tabel 9 disimpulkan kepuasan supervisi pada MTs dan SMK YAPISA berada dalam kategori puas karena dalam meningkatkan pengawasan dan perhatian yang dilakukan kepala sekolah telah tercipta keterikatan pihak sekolah terhadap guru. Adapun rekapitulasi tanggapan guru terhadap kepuasan rekan kerja pada Tabel 10 .

Berdasarkan Tabel 10 disimpulkan bahwa kepuasan rekan kerja pada MTs dan SMK YAPISA ada pada nilai cukup puas karena antara rekan kerja satu dan yang lainnya membentuk rasa kekeluargaan, keharmonisan di dalam sekolah dan luar sekolah. Adapun rekapitulasi tanggapan guru terhadap kepuasan kondisi kerja pada Tabel 11.

Berdasarkan Tabel 11 maka disimpulkan bahwa kepuasan kondisi kerja pada Madrasah Tsanawiyah danSMK YAPISA berada dalam kategori puas dalam membuat lingkungan kerja nyaman serta aman sekolah telah berhasil memberikan kondisi untuk kerja yang dibutuhkan guru. Adapun rekapitulasi tanggapan guru tentang komitmen organisasi seperti pada Tabel 12. 
Tabel 10 Rekapitulasi tanggapan guru mengenai kepuasan rekan kerja

\begin{tabular}{llrl}
\hline No & \multicolumn{1}{c}{ Uraian } & Penilaian responden & Keterangan \\
\hline 1 & Hubungan rekan kerja & 3,45 & Puas \\
2 & Diskusi & 3,43 & Puas \\
3 & Persahabatan & 3,41 & Puas \\
4 & Mendengarkan masalah & 3,47 & Puas \\
5 & Menghargai saat diskusi & 3,43 & Puas \\
6 & Komunikasi & 3,28 Puas \\
7 & Wawasan & 3,02 & Cukup Puas \\
8 & Berbagi ilmu & 3,45 & Puas \\
9 & Kepala sekoah memberi nasihat dan masukan & 3,30 & Cukup Puas \\
10 & Solusi & 3,30 & Cukup Puas \\
Rata-rata & 3,36 & Cukup Puas \\
\hline
\end{tabular}

Tabel 11 Rekapitulasi tanggapan guru mengenai kepuasan kondisi kerja

\begin{tabular}{llrl}
\hline No & \multicolumn{1}{c}{ Uraian } & Penilaian responden & Keterangan \\
\hline 1 & Sirkulasi udara & 3,47 & Puas \\
2 & Temperature udara & 3,68 & Puas \\
3 & Pencahayaan & 3,04 & Cukup puas \\
4 & Bising suara & 3,47 & Puas \\
5 & Akibat bising suara & 3,89 & Puas \\
6 & Kebersihan lingkungan kerja & 3,74 & Puas \\
7 & Fasilitas modern & 3,68 & Puas \\
8 & Kelengkapan fasilitas & 3,60 & Puas \\
9 & Peralatan keselamatan kerja & 3,26 & Cukup puas \\
10 & Kelengkapan peralatan keselamatan kerja & 3,51 & Puas \\
11 & Fasilitas kesehatan & 3,26 & Cukup puas \\
12 & Ruang kesehatan & 3,23 & Cukup puas \\
Rata-rata & 3,50 & Puas \\
\hline
\end{tabular}

Tabel 12 Rekapitulasi tanggapan guru mengenai komitmen organisasi

\begin{tabular}{llrl}
\hline No & \multicolumn{1}{c}{ Uraian } & Penilaian responden & Keterangan \\
\hline 1 & Komitmen lama kerja & 4,64 & Sangat tinggi \\
2 & Perasaan bangga & 4,42 & Sangat tinggi \\
3 & Keterikatan emosional & 4,09 & Tinggi \\
4 & Rasa memiliki & 4,56 & Sangat tinggi \\
5 & Tidak meninggalkan sekolah & 4,28 & Sangat tinggi \\
6 & Komitmen kondisi sekolah & 4,11 & Tinggi \\
7 & Tidak pindah bekerja & 4,17 & Tinggi \\
8 & Kesejahteraan sekolah & 4,56 & Sangat tinggi \\
\hline
\end{tabular}




\begin{tabular}{llrl}
\hline 9 & Perhatian sekolah & 4,31 & Sangat tinggi \\
10 & Komitmen untuk dampak pindah bekerja & 4,19 & Tinggi \\
11 & Komitmen Bekerja tuntas & 3,90 & Tinggi \\
12 & Loyalitas & 4,54 & Sangat tinggi \\
13 & Tanggung jawab pekerjaan & 4,47 & Sangat tinggi \\
14 & Rasa tanggung jawab & 4,51 & Sangat tinggi \\
15 & Etika & 4,61 & Sangat tinggi \\
Rata-rata & 4,35 & Sangat tinggi \\
\hline
\end{tabular}

Berdasarkan Tabel 12 disimpulkan komitmen organisasi guru pada Madrasah Tsanawiyah dan SMK YAPISA termasuk dalam kategori sangat tinggi karena guru menyadari bahwa pekerjaanya merupakan kegiatan yang begitu berarti bagi para anak didik, sehingga dengan pemenuhan dari faktor-faktor kepuaasan cukup guru tetap berkomitmen tinggi terhadap sekolah.

\section{Hasil Uji Faktor-Faktor Kepuasan Kerja Terhadap Komitmen Organisasi}

Berdasarkan perhitungan dengan menggunakan software SPSS for Windows, maka diperoleh data seperti pada Tabel 13.

Tabel 13 Rangkuman hasil perhitungan faktor-faktor kepuasan kerja terhadap komitmen organisasi

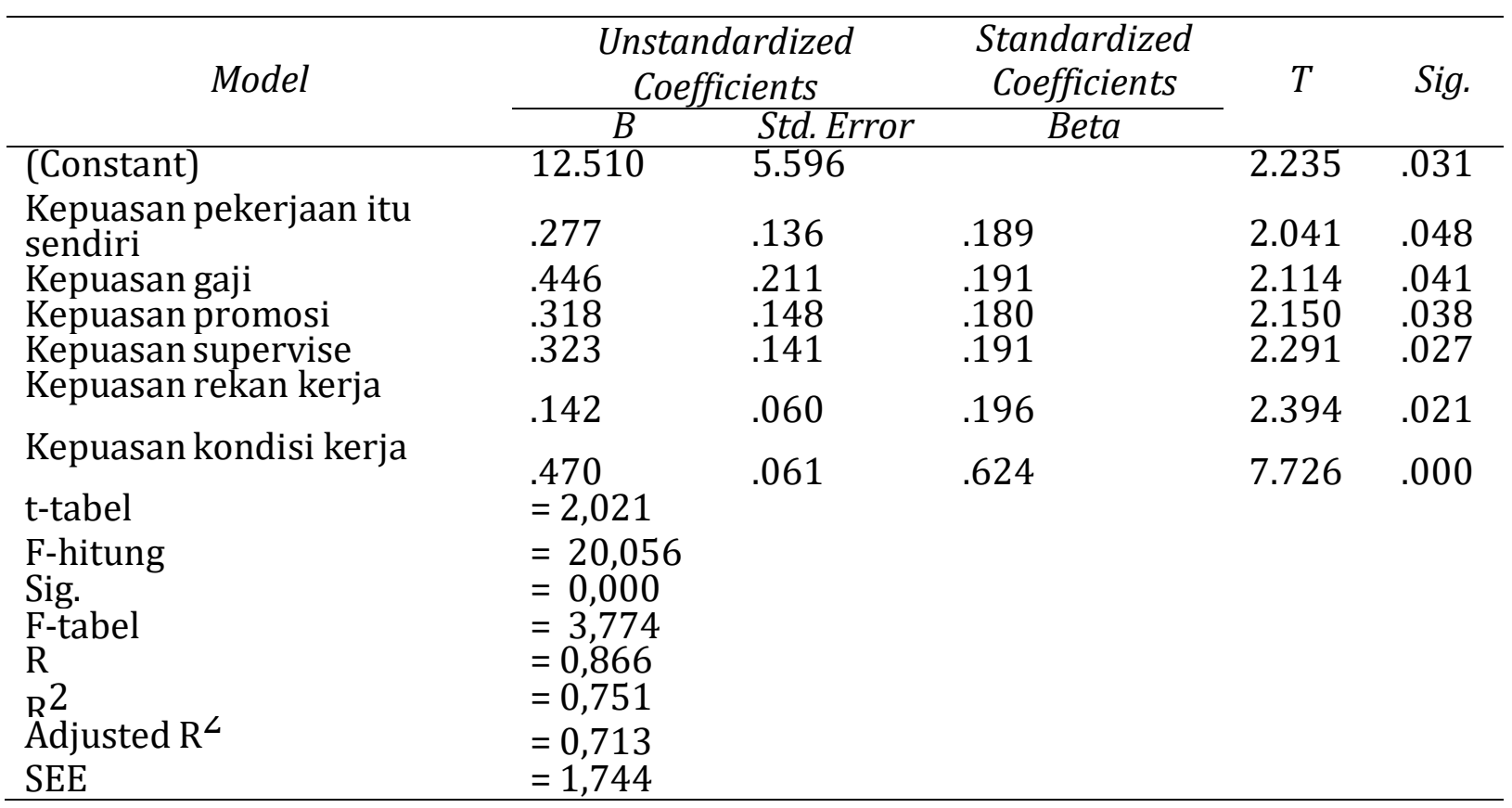

Berdasarkan ringkasan hasil perhitungan menggunakan regresi berganda bahwa yang digunakan dapat menjelaskan 75,1 \% dari variabel dependent. Secara keseluruhan ini signifikan pada tingkat kepercayaan 95\%. (F-hitung 20,056) sehingga model ini cukup memadai untuk digunakan sebagai alat analisis. Secara parsial kepuasan dari pekerjaan itu sendiri, kepuasan gaji, kepuasan promosi, kepuasan supervisi, kepuasan rekan kerja serta kepuasan kondisi kerja berpengaruh terhadapkomitmen organiasasi pada guru MTs dan SMK Terpadu YAPISA Megamendung Kabupaten Bogor. Luthans (2006), menyatakan bahwa apabila seorang pekerja merasa telah terpenuhi semua kebutuhan serta keinginannya oleh 
organisasi tempat bekerja maka dengan penuh rasa kesadaran meningkatkan komitmen dalam diri.

\section{KESIMPULAN DAN IMPLIKASI}

Berdasarkan penelitian yang dilakukan, maka didapatkan beberapa kesimpulan sebagai berikut: 1) Kondisi faktor-faktor kepuasan kerja berada pada ketegoti cukup puas, sedangkan kondisi komitmen organisasi berada pada kategori sangat tinggi; 2) faktor-faktor kepuasan kerja secara simultan berpengaruh positif fan signifikan pada komitmen organisasi; 3) kepuasan pekerjaan itu sendiri, kepuasan gaji, kepuasan promosi, kepuasan supervisi, kepuasan rekan kerja,kepuasan kondisi kerja berpengaruh positif dan signifikan pada komitmen organisasi.

Berdasarkan hasil penelitian, ada beberapa saran yang penulis kemukakan mengenai fakotrfaktor dari kepuasan kerja kerja pada komitmen pada organisasi, yang diuraikan sebagai berikut: 1) Sebaiknya pihak sekolah mempekerjakan karyawan khusus untuk menangani peralatan belajar mengajardigunakan oleh guru; 2) Sebaiknya pihak sekolah membuat kebijakan baru untuk menaikan gaji sesuai upah minimum, dengan kriterianya yaitu prestasi kerja guru; 3) Sebaiknya sekolah memperbaiki sistem informasi tentang promosi jabatan juga membuat cara penyebaran informasi yang terbuka dan transparantuntuksemua guru yang memenuhisyarat; 4) Sebaiknya pengawasan tetap dilakukan meskipun guru diberikan pujian terhadap guru yang berprestasi; 5) Sebaiknya pertukaran wawasan dapat dilakukan lebih intensif ketika wawasan baru telah diterima lewat pelatihan dan juga study banding; 6) Sebaiknya sekolah menambah atau membuat pencahayaan yang baik untuk kondisi ruangan guru yang lebih nyaman; 7) Sebaiknya sekolah lebih memberikan motivasi pada guru agar bersemangat menyelesaikan bekerja tuntas yang merupakan kewajiban setiap guru, dengan mengadakan evaluasi pekerjaan dan pemenuhan kebutukan yang dibutuhkan oleh guru dapat membantu agar tetap bekerja tuntas dari seluruh beban pekerjaanya; 8) Sebaiknya yayasan memberikan tenaga pengajar pengganti untuk mengganti guru yang absen dengan memberikan guru piket sebagai penanggung jawab untuk mengajar ketika guru tidak masuk; 9) Bagi peneliti selanjutnya, diharapkan mampu mengebangkan penelitian dengan menambah populasi agar penelitian lebih luas agar pengaruh lain untuk komitmen organisasi seperti pengalaman kerja, karakteristik pekerjaan, karakteristik struktur, interaksi tugas bisa ditingkatkan.

\section{DAFTAR PUSTAKA}

Adiwinata Irvan, Susanto Eddy M. 2014. Pengaruh Kepuasan Kerja dan Motivasi Kerja terhadap Produktivitas Kerja Karyawan pada CV Intaf Lumajang. Jurnal Penelitian. Vol 2, No 1. Surabaya. Program Manajemen Bisnis Universitas Kristen Petra.

Arikunto, Suharsimi. 2006. Prosedur Penelitian. Edisi Revisi VI. Jakarta. Rineka Cipta.

Febriyana, Wanda. 2015. Pengaruh Kepuasan Kerja terhadap Kinerja Karyawan pada PT Khabepe Chakra Bandung. Jurnal Penelitian. Bandung. Fakultas Ekonomi dan Bisnis Universitas Telkom.

Flippo, Edwin. 2006. Personel Managemen (Manajemen Personalia). Terjemahan Alponso S. Jakarta. Erlangga.

Ghozali, Imam. 2005. Aplikasi Analisis Multivariate Program SPSS. Semarang. Badan Penerbit UNDIP.

Handoko, T. Hani. 2002. Manajemen Personalia Dan Sumber Daya Manusia. Edisi Kedua. Yogyakarta. BPFE.

Hasibuan, Malayu S.P. 2008. Manajemen Sumber Daya Manusia. Jakarta. Bumi Aksara. Indriantoro, Suwandi. 2009. Peran Budaya Organisasi terhadap 
Intense Turnover. Jurnal Psikologi. Vol 09. Yogyakarta. Universitas Gajah Mada.

Luthans, Fred. 2006. Perilaku Organisasi. Edisi Sepuluh. Yogyakarta. Andy Offset.

Mangkunegara, Anwar P. 2002. SDM Perusahaan. Bandung. Remaja Rosdakarya.

Nazir, Muhammad. 2003. Metode Penelitian. Cetakan Kelima. Jakarta Indonesia. Ghalia Puspasari, Maria. A.W. 2014. Pengaruh Motivasi dan Budaya Organisasi terhadap Komitmen Organisasi dan Kinerja karyawan pada PT Citra Sena Suksess Semarang. Jurnal Penelitian.Yogyakarta. Universitas Atma Jaya.

Robbins, S.P. 2003. Prinsip-Prinsip Perilaku Organisasi. Edisi Kelima. Jakarta. Penerbit Erlangga.

Sopiah. 2008. Perilaku Organisasional. Yogyakarta. CV Andi Offset.

Sugiyono. 2013. Metode Penelitian Kualitatif, Kuantitatif dan Kombinasi, Edisi ketiga. Bandung. Alfabeta. 